\title{
Therapeutic Endoscopic Ultrasound
}

\author{
Barham K. Abu Dayyeh, MD, MPH, and Michael J. Levy, MD
}

Dr. Abu Dayyeh is an Assistant Professor of Medicine and Dr. Levy is a Professor of Medicine, both in the Division of Gastroenterology and Hepatology at Mayo Clinic in Rochester, Minnesota.

Address correspondence to:

Dr. Michael J. Levy

Division of Gastroenterology

and Hepatology

Mayo Clinic

200 First Street SW

Rochester, MN 55905;

Tel: 507-266-6931;

Fax: 507-266-3939;

E-mail: levy.michael@mayo.edu

Keywords

Endoscopic ultrasound, interventions, biliary

disease, pancreatic disease

\begin{abstract}
Endoscopic ultrasound (EUS) is a viable and often preferred alternative to interventional and radiologic procedures, and the therapeutic applications of EUS continue to evolve. This evolution was catalyzed by the introduction of linear echoendoscopes that provide continuous imaging and observation of needles and by therapeutic devices that pass through large-caliber working channels. In this paper, we will discuss the spectrum of EUS-guided interventions that are currently available and in development.
\end{abstract}

$\mathrm{E}$ ndoscopic ultrasound (EUS) has evolved from a purely diagnostic imaging modality to an interventional procedure that provides a minimally invasive alternative to interventional radiologic and surgical techniques. This transition was ushered by the introduction of linear echoendoscopes that provide continuous imaging and observation of needles and by therapeutic devices that pass through large-caliber working channels. The purpose of this paper is to discuss a spectrum of EUS-guided interventions, including drainage of the pancreas, gallbladder, and other fluid collections; access to the pancreatic and biliary systems; celiac plexus interventions; and ablative therapies.

\section{Endoscopic Ultrasound-Guided Drainage of the Pancreas, Gallbladder, and Other Fluid Collections}

\section{Pancreatic Fluid Collections}

Pancreatic fluid collections develop following pancreatic duct disruption with leakage of pancreatic juices in patients with acute or chronic pancreatitis, trauma, surgery, or neoplasia. Before selecting a therapeutic strategy, it is essential to characterize the fluid collection as either a pseudocyst or a walled-off pancreatic necrosis, assess its proximity to the gastric or bowel wall, and determine the presence of intervening structures. EUS-guided transmural drainage tech- 
niques showed superior technical and treatment success rates and more favorable safety profiles than traditional, non-EUS approaches in 2 prospective randomized trials (Figure 1)., ${ }^{1,2}$ The advantages of EUS include the ability to access collections that do not cause luminal compression, to distinguish among types of collections (pseudocyst, necrosis, or cystic neoplasm), and to minimize complications via optimal selection of the puncture site to avoid blood vessels. Technical and treatment success rates of EUS-guided drainage have been reported to be $95 \%$ and $85 \%$, respectively, and complications (including perforation, air embolism, bleeding, systemic infection, and stent migration) have occurred at rates of $0-30 \% .^{3-6}$ This wide range of complication rates reflects the heterogeneity of drainage techniques, endoscopist experience, and fluid collection type, size, and location.

In a recent study of 148 patients who underwent EUS-guided drainage of pancreatic collections, Varadarajulu and colleagues reported an infection rate of $2.7 \%$, a perforation rate of $1.3 \%$, a bleeding rate of $0.67 \%$, and a stent migration rate of $0.67 \% .^{7}$ The researchers did not have any cases of air embolism, and transgastric drainage of an uncinate process collection was associated with higher perforation rates than drainage of collections in other areas of the pancreas ( $0 \%$ vs $50 \% ; P=.0005)$. $^{7}$

However, it should be noted that skilled physicians with extensive experience performing non-EUS approaches have technical and clinical success rates comparable to the rates associated with EUS-guided approaches. For most techniques, the preferred approach is influenced by a number of patient and procedurerelated factors, although the experience and outcomes of individual endoscopists should be heavily considered in the selection process.

\section{The Gallbladder}

Gallstone disease and its associated complicationsincluding biliary colic, cholecystitis, choledocholithiasis, and pancreatitis-are leading causes of morbidity and hospital admissions in the developed world ${ }^{8}$ Cholecystectomy is the treatment of choice for symptomatic gallstone disease, with more than 700,000 cholecystectomies performed annually in the United States. ${ }^{9}$

Alternatives to cholecystectomy are performed in patients with prohibitive surgical risks, such as unstable medical comorbidities or hostile surgical abdomens from previous surgery. These alternative procedures include percutaneous cholecystostomy and endoscopic retrograde transpapillary gallbladder drainage during endoscopic retrograde cholangiopancreatography (ERCP). ${ }^{10,11}$ EUS has been successfully utilized for single-step EUS-guided transgastric or transduodenal gallbladder drainage with placement of a modified covered self-expandable metal

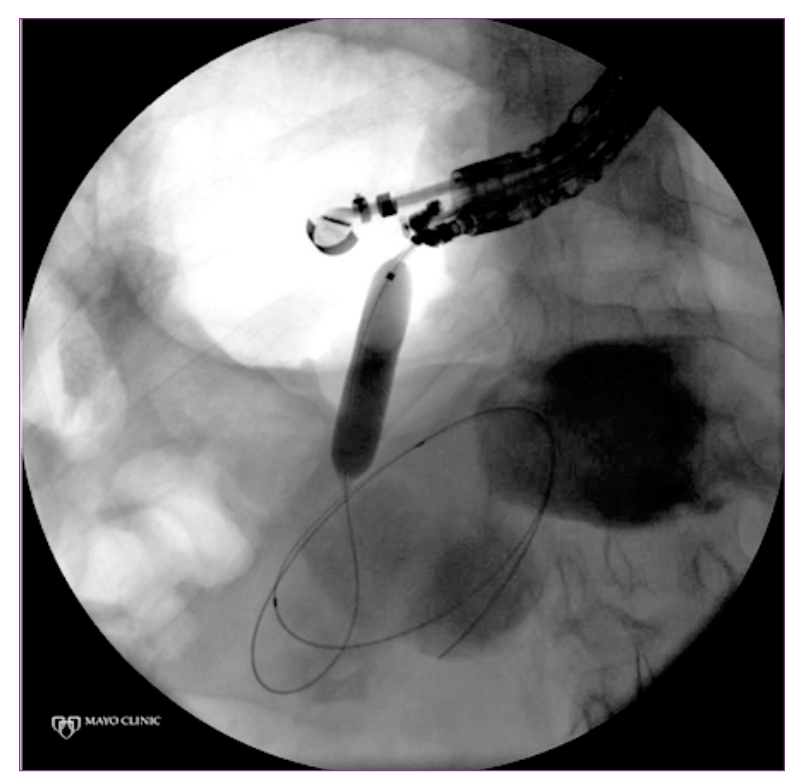

Figure 1. Endoscopic ultrasound (EUS)-guided transmural drainage of a pancreatic fluid collection. A guidewire was passed into the pancreatic fluid collection from the gastric wall through an EUS-guided needle, and the tract was dilated over the guidewire with a dilating balloon as shown.

stent in patients with acute cholecystitis who are unsuitable for cholecystectomy. The modified stent utilized in this approach is a partially covered metal stent with a midshaft diameter of $10 \mathrm{~mm}$ and a length of 4-7 cm. In addition, the stent has enlarged, uncovered end flairs with a 22-mm external diameter that provide tissue apposition and prevent migration. A study of 15 patients found technical and functional success rates of $100 \%$ when using EUS to place these stents into the gallbladder for treatment of acute cholecystitis. None of the patients had recurrent cholecystitis during a median follow-up period of 145 days, and 2 patients developed pneumoperitoneum that was managed conservatively. ${ }^{12}$ The advantage of this EUS approach is that it can be performed in the presence of ascites when good apposition can be achieved between the gallbladder and the gastric or duodenal wall; in addition, the utilization of large-caliber metal stents decreases the need for repeat procedures for endoprosthesis exchange.

\section{Pelvic Abscesses}

Pelvic abscesses result from a variety of inflammatory, infectious, ischemic, and postsurgical processes. Given the complex and relatively sheltered pelvic anatomy within the bony pelvis, rectal EUS potentially offers multiple advantages over traditional percutaneous or surgical techniques. EUS enables bedside drainage, which is important for critically ill patients. The ability of EUS to provide internal drainage (via placement of double-pigtail stents) 


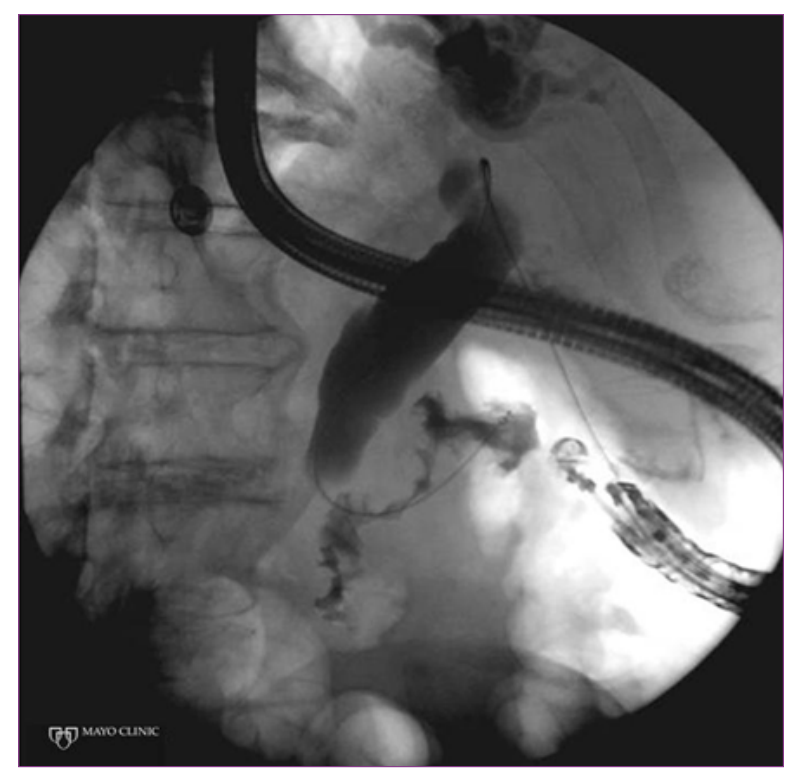

Figure 2. Endoscopic ultrasound (EUS)-guided biliary access via a transhepatic (hepaticogastrostomy) approach. A guidewire was passed via an EUS-guided needle through the gastric wall into a dilated left intrahepatic duct and was maneuvered distally to coil in the duodenum through the major papilla.

or external drainage (via placement of a single-pigtail stent and a secondary flushing catheter) enables shorter hospital stays and minimal interruption of patient activity. EUS-guided approaches are well suited for fluid collections that are more than $4 \mathrm{~cm}$ in diameter, have mature walls, and are located above the dentate line and within $2 \mathrm{~cm}$ of the EUS transducer. In these settings, the technique has proven to be both safe and effective. ${ }^{13-17}$

\section{Endoscopic Ultrasound-Assisted Access to the Biliary and Pancreatic Systems}

The increased frequency and improved survival rates of gastric and pancreaticobiliary surgeries_-including Billroth II operation, pancreaticoduodenectomy (Whipple procedure), distal pancreatectomy, lateral pancreaticojejunostomy, and Roux-en-Y hepaticojejunostomy-are increasing the need to manage surgical complications such as stenosis at the site of choledochojejunostomy, hepaticojejunostomy, or pancreaticojejunostomy secondary to disease recurrence or benign stricturing. ${ }^{18}$ The altered surgical anatomy of these patients complicates ERCP approaches. Even with native anatomy, ERCP may fail to access the pancreatic or biliary tree secondary to anatomic variants (eg, periampullary diverticulum) or malignant or benign processes that obstruct or impinge on the ducts. Finally, even in the absence of complicating factors at expert centers, ERCP is unsuccessful at

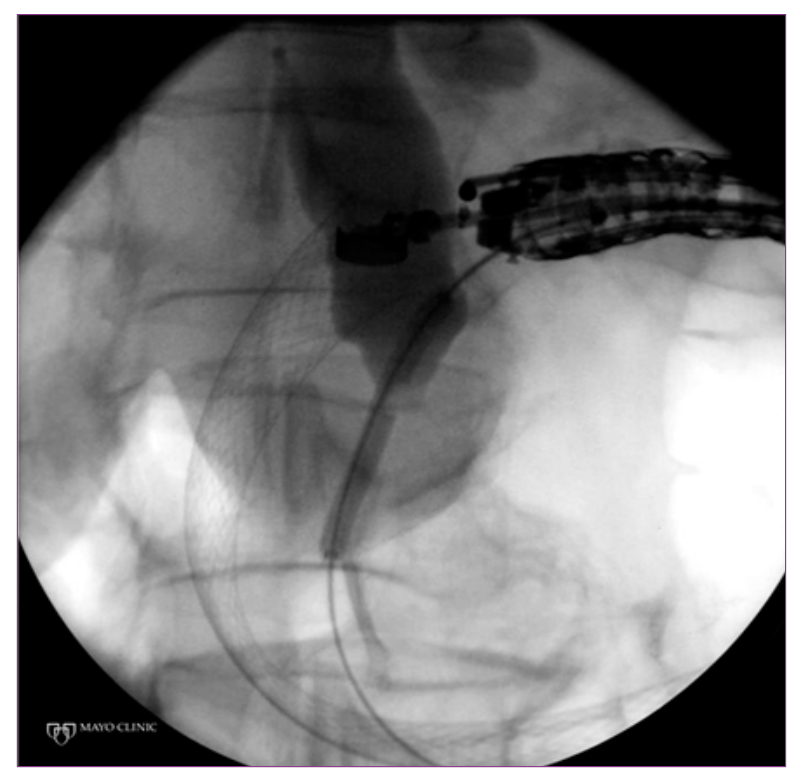

Figure 3. Endoscopic ultrasound (EUS)-guided biliary access via an extrahepatic (choledochoduodenostomy) approach. A guidewire was passed via an EUS-guided needle through the duodenal bulb into a dilated common bile duct and was maneuvered distally to the duodenum through the major papilla. The tract was dilated with a dilating balloon. An enteral metal stent was present in the duodenum which prevented retrograde access during endoscopic retrograde cholangiopancreatography.

obtaining access and/or drainage in as many as 5\% of patients. Until recently, such patients could be managed only via a percutaneous or surgical approach. An emerging alternative is EUS-assisted pancreaticobiliary access and drainage.

These techniques can be broadly categorized as either transpapillary/transanastomotic or transluminal. The transpapillary or transanastomotic approach involves EUS-guided passage of a 19-gauge or 22-gauge needle as well as passage of a 0.035 -inch or smaller guidewire through the gastric or duodenal wall into the pancreatic or bile duct and across the papilla or anastomosis into the small bowel. Balloon dilation and plastic stent insertion can then be achieved via a retrograde (rendezvous) approach with the aid of a side-viewing duodenoscope or extended-forward-viewing endoscope that is inserted following removal of the echoendoscope. The entire procedure, including stent placement, may also be performed via an antegrade approach with the echoendoscope.

The transluminal (or transmural) route may be used when transpapillary or transanastomotic stenting fails. With this approach, the distal end of the stent is placed within the pancreatic duct, and the entire examination is performed via an antegrade approach, thus draining the pancreatic duct into the stomach. Although the translu- 
minal approach could provide adequate palliation in a patient with limited life expectancy due to a malignant process, its role is less clear in benign conditions, where its benefits must be weighed against the long-term management of the created pancreaticogastric fistula.

\section{Biliary Interventions}

EUS-guided biliary interventions may be indicated for treatment or palliation of benign or malignant biliary obstruction after failed ERCP. EUS-guided biliary interventions can be performed via a transhepatic approach (hepaticogastrostomy) from the proximal stomach or via an extrahepatic approach (choledochoduodenostomy) from the duodenum, where the extrahepatic bile duct (either intrapancreatic or suprapancreatic) is accessed for transpapillary or transluminal interventions (Figures 2 and 3). The hepaticogastrostomy technique has a pooled technical success rate of $73 \%$ in studies with at least 3 patients, with an incidence rate of $10-15 \%$ for major complications. ${ }^{19-22}$ Similarly, the choledochoduodenostomy technique has a pooled technical success rate of $83 \%$, with an incidence rate of $10-15 \%$ for major complications. . $^{21,23-31}$ Major complications included pneumoperitoneum, hemorrhage, cholangitis, biloma, pancreatitis, bile peritonitis, and duodenal perforation.

These preliminary data are promising, and there is potential to use these techniques in a variety of clinical scenarios. For example, a group recently reported the use of the transluminal hepaticogastrostomy technique to perform balloon sphincteroplasty for treatment of choledocholithiasis in Roux-en-Y gastric bypass patients. Another group reported improved success rates and safety for rendezvous choledochoduodenostomy compared to precut sphincterotomy in patients with difficult biliary access. ${ }^{22,30}$

\section{Pancreatic Interventions}

EUS-guided pancreatic interventions are commonly indicated after failed ERCP for decompression of the pancreatic duct in patients with a stone or stricture from chronic pancreatitis, postsurgical pancreaticojejunal anastomotic stenosis, or failure of prophylactic placement of a pancreatic stent after endoscopic ampullectomy (Figure 4). The pooled technical success rate of EUS-guided pancreatic interventions was approximately $77 \%$ in case series of at least 3 patients; major complications (including bleeding, perforation, pancreatitis, and hematoma formation) occurred at a rate of approximately $10 \% .^{28,31-38}$ However, the definitions of clinical success and adverse events were not standardized across these studies; thus, firm conclusions cannot be determined solely from these observational data, particularly due to the potential for publication bias and the complex nature of these procedures.

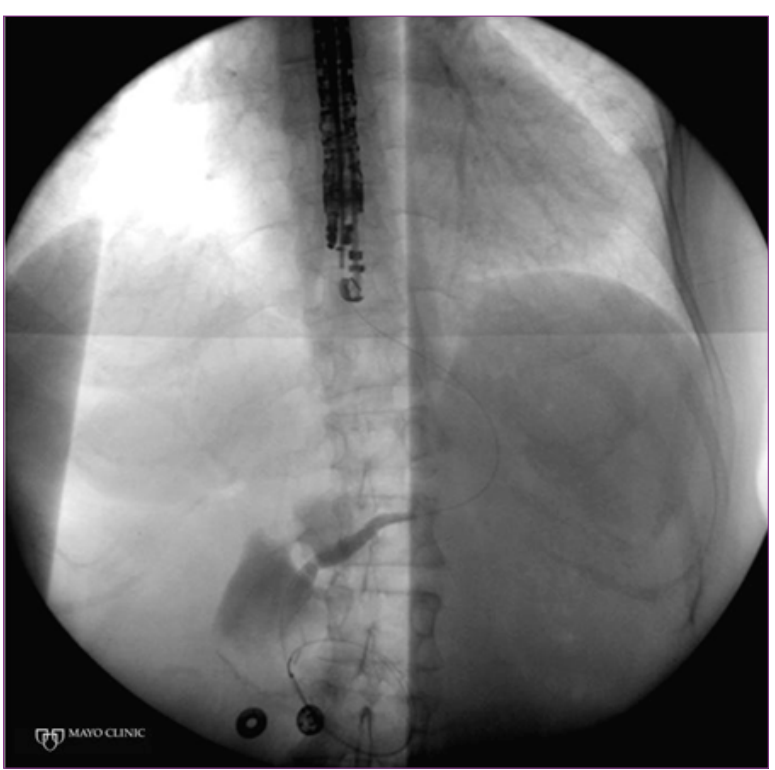

Figure 4. Endoscopic ultrasound (EUS)-guided pancreatic intervention in a patient with postsurgical pancreaticojejunal anastomotic stenosis following a pancreaticoduodenectomy. A guidewire was passed via an EUS-guided needle through the gastric wall into the pancreatic duct and was maneuvered across the strictured pancreaticojejunal anastomosis. The tract was dilated with a dilating balloon prior to plastic stent placement.

\section{Endoscopic Ultrasound-Guided Celiac Plexus Interventions}

Despite medical therapy, intractable abdominal pain commonly develops in patients with pancreatic cancer and/or chronic pancreatitis. Celiac plexus block and neurolysis $(\mathrm{CPN})$ can improve pain and decrease opioid requirements in these patients as well as help alleviate associated dry mouth, constipation, nausea, vomiting, drowsiness, delirium, and impaired immune function..$^{39}$ Traditionally, the percutaneous computed tomography-guided paraspinal or transabdominal approach was utilized to perform these interventions with rare but serious complications such as paraplegia and pneumothorax. EUS provides a more direct and targeted approach secondary to better delineation of anatomic landmarks, close proximity of the transducer to the celiac plexus, and visualization of neural ganglionic structures that are not visible with other imaging modalities (Figure 5).

A recent Cochrane systematic review identified 6 randomized controlled trials (RCTs) that evaluated percutaneous methods of CPN in 358 patients with pancreatic cancer who were followed for at least 4 weeks. At that time, CPN was associated with statistically significant improvement in pain control compared to analgesic ther- 


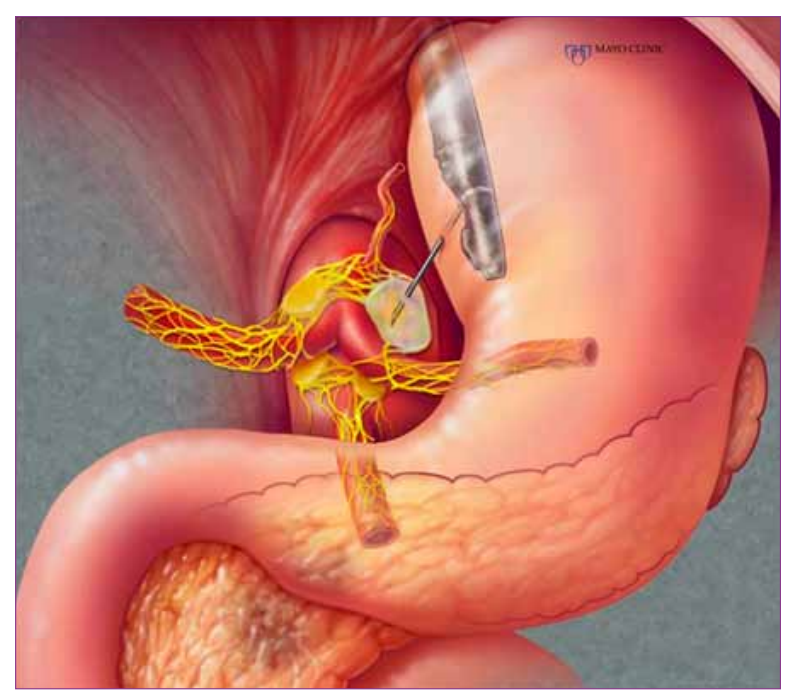

Figure 5. Endoscopic ultrasound-guided celiac plexus intervention. A direct celiac ganglia neurolysis is shown.

apy alone (mean difference of -0.42 in favor of CPN, with a $95 \%$ confidence interval of -0.70 to $-0.13 ; P=.004)$; the $\mathrm{CPN}$ group also had significantly lower opioid consumption and fewer adverse events. ${ }^{40}$ However, these findings were associated with a significant degree of heterogeneity, and further studies are needed to compare the percutaneous and EUS approaches. The only RCT conducted thus far on this issue involved 96 patients who were randomized to either early EUS-guided CPN (EUS-CPN) or conventional care; EUS-CPN was found to be superior to conventional care for pain control at 1 and 3 months, with lower opioid consumption at 3 months in the EUS-CPN group. ${ }^{41}$

EUS-CPN is typically performed in the outpatient setting with moderate-to-heavy sedation, usually during the index examination for pancreatic cancer diagnosis and staging. Contraindications to EUS-CPN include uncorrectable coagulopathy, inadequate sedation, and altered anatomy that prevents adequate visualization of the celiac anatomy. Three techniques have been reported for performing EUS-CPN: CPN, celiac ganglia neurolysis (CGN), and broad plexus neurolysis (BPN). In EUS-CPN, the first and most widely used approach, a 5-mm area caudal and anterior to the celiac trunk is targeted with a 22-gauge EUS needle and injected with a mixture of bupivacaine $(0.25-1 \%)$ and ethanol (95-99\%). The entire volume can be injected at a single site midline; however, some studies have suggested that bilateral injections at either side of the celiac trunk are more efficacious. ${ }^{42,43}$ In CGN, EUS is used to target the injection into the celiac ganglia with the hope that this method will enhance safety, efficacy, and durability. ${ }^{44}$ Finally, in BPN, the entire injection is given in an area anterior and caudal to the superior mesenteric artery trunk. ${ }^{45}$ Comparative studies are currently underway to evaluate the safety and efficacy of these techniques.

Given the longer and more common use of percutaneous $\mathrm{CPN}$ techniques, the relative frequency of complications is better defined from this literature; these complications include local pain (96\%), diarrhea (9-44\%), transient hypotension (8-38\%), constipation (40\%), nausea and vomiting (41\%), and lethargy (49\%). ${ }^{46,47}$ In a meta-analysis, severe complications were reported in 13 of 628 patients (2\%) and included neurologic complications, pneumothorax, and hematuria. ${ }^{47} \mathrm{~A}$ similar complication profile has been reported in the EUS-CPN literature, although there have been no reports of severe complications such as paraplegia. ${ }^{44,45,48-51}$ Neurologic complications, including paraplegia, are thought to develop secondary to ischemia or direct injury to the spinal cord or somatic nerves; thus, the EUS's anterior access to the celiac plexus is a theoretical advantage, as it avoids the retrocrural space. However, we are aware of at least 1 case of paraplegia caused by EUS-CPN, and more severe complications will likely be reported as the technique matures and results are reported from larger trials.

\section{Endoscopic Ultrasound Radiofrequency Ablation, Brachytherapy, and Injection Ablative Therapies}

An exciting and developing field in interventional EUS involves targeted delivery of an ablative device or chemical for the treatment of gastrointestinal tumors, malignancies, and metastases. The research thus far consists of only animal feasibility studies and limited human pilot data, although this field is rapidly evolving. EUS has been used to deliver radiofrequency ablation and photodynamic therapy catheters for targeted tissue ablation in the pancreas, spleen, and the left lobe of the liver. ${ }^{52,53}$ Furthermore, pilot studies in patients with unresectable pancreatic cancer have demonstrated the feasibility of EUS-delivered brachytherapy or radioactive iodine-125 seeds to deliver targeted tissue radiation for the localized treatment of cancer. ${ }^{54,55}$ Finally, EUS has also been used for the precise delivery of small radiopaque markers (sterilized gold fiducial) into the periphery of malignant lesions for better targeting of focused beams of radiation to the intended organs (such as the pancreas and prostate)..$^{56,57}$

EUS has also been used to inject ethanol for the ablation of pancreatic and other gastrointestinal cysts, tumors, and metastases. Recently, Levy and colleagues reported a case series of 8 patients with symptomatic insulinomas who were poor surgical candidates or had incomplete surgical resections; these patients were successfully treated with EUS or intraoperative ultrasound (IOUS)-guided fine-needle injection (FNI) of ethanol..$^{5}$ No complications devel- 
oped during or following EUS-FNI. During IOUS-FNI, minor peritumoral bleeding occurred in 1 patient, but it did not require intervention. Another patient developed a $1.7-\mathrm{cm}$ fluid collection and an 8-cm pseudocyst, neither of which required intervention. A third patient who underwent IOUS-FNI was rehospitalized due to pancreatitis and a peripancreatic fluid collection. She was discharged 3 days later following conservative care and is currently undergoing surveillance imaging. ${ }^{58}$ Furthermore, $\mathrm{Oh}$ and colleagues recently reported results of EUS-guided injection and lavage with ethanol, followed by injection of paclitaxel into pancreatic cysts in 52 patients (median follow-up, 21.7 months). ${ }^{59} \mathrm{~A}$ complete response (defined as elimination of the cyst as evidenced by cross-sectional imaging) was achieved in 29 patients (56\%), a partial response was achieved in 6 patients (12\%), persistent cysts were seen in 12 patients (23\%), and 5 patients $(9 \%)$ were lost to followup. On multivariate analysis, the initial cyst volume was the only significant predictor of resolution. Mild pancreatitis and splenic vein obliteration each occurred in 1 patient. ${ }^{59}$ Another group used only EUS-guided ethanol lavage for treatment of pancreatic cysts and reported a complete resolution rate of $33 \%$ (12/36 cysts), a result that was durable after a median follow-up period of 26 months following initial documentation of cyst resolution. ${ }^{60,61}$

\section{Other Endoscopic Ultrasound-Guided Interventions}

Another novel application of interventional EUS involves local treatment of unresectable pancreatic cancer via local injection of a chemotherapeutic agent (such as gemcitabine), cytoimplants (sensitized cultures of lymphocytes), or antitumor viral and gene therapy vectors. ${ }^{62,63}$ There are also emerging data on the use of EUS for therapy of a variety of vascular lesions (such as refractory varices, aneurysms, and Dieulafoy lesions) via coil embolization or sclerotherapy. ${ }^{64-66}$

\section{Conclusion}

EUS is a viable and often preferred alternative to interventional and radiologic procedures, and the therapeutic applications of EUS continue to evolve. The high technical demands and complexity of EUS-guided interventions will necessitate adequate training and the development of new techniques and equipment to facilitate their use. In addition, more data are needed to accurately determine the risks and long-term outcomes of these interventions before clarifying their role. Until then, EUS-guided interventions must be carefully considered and performed by appropriately experienced endoscopists and a multidisciplinary team.

\section{References}

1. Varadarajulu S, Christein JD, Tamhane A, Drelichman ER, Wilcox CM. Prospective randomized trial comparing EUS and EGD for transmural drainage of pancreatic pseudocysts (with videos). Gastrointest Endosc. 2008;68:1102-1111.

2. Park DH, Lee SS, Moon SH, et al. Endoscopic ultrasound-guided versus conventional transmural drainage for pancreatic pseudocysts: a prospective randomized trial. Endoscopy. 2009;41:842-848.

3. Varadarajulu S, Tamhane A, Blakely J. Graded dilation technique for EUSguided drainage of peripancreatic fluid collections: an assessment of outcomes and complications and technical proficiency (with video). Gastrointest Endosc. 2008;68:656-666.

4. Seifert H, Biermer M, Schmitt W, et al. Transluminal endoscopic necrosectomy after acute pancreatitis: a multicentre study with long-term follow-up (the GEPARD study). Gut. 2009;58:1260-1266.

5. Voermans RP, Eisendrath P, Bruno MJ, Le Moine O, Devière J, Fockens P; ARCADE group. Initial evaluation of a novel prototype forward-viewing US endoscope in transmural drainage of pancreatic pseudocysts (with videos). Gastrointest Endosc. 2007;66:1013-1017.

6. Lopes CV, Pesenti C, Bories E, Caillol F, Giovannini M. Endoscopic ultrasound-guided endoscopic transmural drainage of pancreatic pseudocysts and abscesses. Scand J Gastroenterol. 2007;42:524-529.

7. Varadarajulu S, Christein JD, Wilcox CM. Frequency of complications during EUS-guided drainage of pancreatic fluid collections in 148 consecutive patients. J Gastroenterol Hepatol. 2011;26:1504-1508.

8. Stinton LM, Myers RP, Shaffer EA. Epidemiology of gallstones. Gastroenterol Clin North Am. 2010;39:157-169, vii.

9. Marschall HU, Einarsson C. Gallstone disease. J Intern Med. 2007;261:529-542.

10. Ginat D, Saad WE. Cholecystostomy and transcholecystic biliary access. Tech Vasc Interv Radiol. 2008;11:2-13.

11. Itoi T, Coelho-Prabhu N, Baron TH. Endoscopic gallbladder drainage for management of acute cholecystitis. Gastrointest Endosc. 2010;71:1038-1045.

12. Jang JW, Lee SS, Park do H, Seo DW, Lee SK, Kim MH. Feasibility and safety of EUS-guided transgastric/transduodenal gallbladder drainage with single-step placement of a modified covered self-expandable metal stent in patients unsuitable for cholecystectomy. Gastrointest Endosc. 2011;74:176-181.

13. Varadarajulu S, Drelichman ER. EUS-guided drainage of pelvic abscess (with video). Gastrointest Endosc. 2007;66:372-376.

14. Trevino JM, Drelichman ER, Varadarajulu S. Modified technique for EUS-guided drainage of pelvic abscess (with video). Gastrointest Endosc. 2008;68:1215-1219.

15. Giovannini M, Bories E, Moutardier V, et al. Drainage of deep pelvic abscesses using therapeutic echo endoscopy. Endoscopy. 2003;35:511-514.

16. Varadarajulu S, Drelichman ER. Effectiveness of EUS in drainage of pelvic abscesses in 25 consecutive patients (with video). Gastrointest Endosc. 2009;70: 1121-1127.

17. Puri R, Eloubeidi MA, Sud R, Kumar M, Jain P. Endoscopic ultrasoundguided drainage of pelvic abscess without fluoroscopy guidance. J Gastroenterol Hepatol. 2010;25:1416-1419.

18. Sohn TA, Yeo CJ, Cameron JL, Iacobuzio-Donahue CA, Hruban RH, Lillemoe KD. Intraductal papillary mucinous neoplasms of the pancreas: an increasingly recognized clinicopathologic entity. Ann Surg. 2001;234:313-321; discussion 321-322.

19. Bories E, Pesenti C, Caillol F, Lopes C, Giovannini M. Transgastric endoscopic ultrasonography-guided biliary drainage: results of a pilot study. Endoscopy. 2007;39:287-291.

20. Will U, Thieme A, Fueldner F, Gerlach R, Wanzar I, Meyer F. Treatment of biliary obstruction in selected patients by endoscopic ultrasonography (EUS)guided transluminal biliary drainage. Endoscopy. 2007;39:292-295.

21. Maranki J, Hernandez AJ, Arslan B, et al. Interventional endoscopic ultrasound-guided cholangiography: long-term experience of an emerging alternative to percutaneous transhepatic cholangiography. Endoscopy. 2009;41:532-538.

22. Weilert F, Binmoeller KF, Marson F, Bhat Y, Shah JN. Endoscopic ultrasoundguided anterograde treatment of biliary stones following gastric bypass. Endoscopy. 2011;43:1105-1108.

23. Burmester E, Niehaus J, Leineweber T, Huetteroth T. EUS-cholangiodrainage of the bile duct: report of 4 cases. Gastrointest Endosc. 2003;57:246-251. 24. Püspök A, Lomoschitz F, Dejaco C, Hejna M, Sautner T, Gangl A. Endoscopic ultrasound-guided therapy of benign and malignant biliary obstruction: a case series. Am J Gastroenterol. 2005;100:1743-1747. 
25. Yamao K, Bhatia V, Mizuno N, et al. EUS-guided choledochoduodenostomy for palliative biliary drainage in patients with malignant biliary obstruction: results of long-term follow-up. Endoscopy. 2008;40:340-342.

26. Tarantino I, Barresi L, Repici A, Traina M. EUS-guided biliary drainage: a case series. Endoscopy. 2008;40:336-339.

27. Itoi T, Itokawa F, Sofuni A, et al. Endoscopic ultrasound-guided choledochoduodenostomy in patients with failed endoscopic retrograde cholangiopancreatography. World J Gastroenterol. 2008;14:6078-6082.

28. Brauer BC, Chen YK, Fukami N, Shah RJ. Single-operator EUS-guided cholangiopancreatography for difficult pancreaticobiliary access (with video). Gastrointest Endosc. 2009;70:471-479.

29. Komaki T, Kitano M, Sakamoto H, Kudo M. Endoscopic ultrasonographyguided biliary drainage: evaluation of a choledochoduodenostomy technique. Pancreatology. 2011;11(suppl 2):47-51.

30. Dhir V, Bhandari S, Bapat M, Maydeo A. Comparison of EUS-guided rendezvous and precut papillotomy techniques for biliary access (with videos). Gastrointest Endosc. 2012;75:354-359.

31. Shah JN, Marson F, Weilert F, et al. Single-operator, single-session EUSguided anterograde cholangiopancreatography in failed ERCP or inaccessible papilla. Gastrointest Endosc. 2012;75:56-64.

32. François E, Kahaleh M, Giovannini M, Matos C, Devière J. EUS-guided pancreaticogastrostomy. Gastrointest Endosc. 2002;56:128-133.

33. Mallery S, MatlockJ, Freeman ML. EUS-guided rendezvous drainage of obstructed biliary and pancreatic ducts: report of 6 cases. Gastrointest Endosc. 2004;59:100-107.

34. Kahaleh M, Hernandez AJ, Tokar J, Adams RB, Shami VM, Yeaton P. EUSguided pancreaticogastrostomy: analysis of its efficacy to drain inaccessible pancreatic ducts. Gastrointest Endosc. 2007;65:224-230.

35. Tessier G, Bories E, Arvanitakis M, et al. EUS-guided pancreatogastrostomy and pancreatobulbostomy for the treatment of pain in patients with pancreatic ductal dilatation inaccessible for transpapillary endoscopic therapy. Gastrointest Endosc. 2007;65:233-241.

36. Will U, Fueldner F, Thieme AK, et al. Transgastric pancreatography and EUSguided drainage of the pancreatic duct. J Hepatobiliary Pancreat Surg. 2007;14:377-382. 37. Kinney TP, Li R, Gupta K, et al. Therapeutic pancreatic endoscopy after Whipple resection requires rendezvous access. Endoscopy. 2009;41:898-901.

38. Barkay O, Sherman S, McHenry L, et al. Therapeutic EUS-assisted endoscopic retrograde pancreatography after failed pancreatic duct cannulation at ERCP. Gastrointest Endosc. 2010;71:1166-1173.

39. Ventafridda V, Tamburini M, Caraceni A, De Conno F, Naldi F. A validation study of the WHO method for cancer pain relief. Cancer. 1987;59:850-856. 40. Arcidiacono PG, Calori G, Carrara S, McNicol ED, Testoni PA. Celiac plexus block for pancreatic cancer pain in adults. Cochrane Database Syst Rev. 2011;(3):CD007519. 41. Wyse JM, Carone M, Paquin SC, Usatii M, Sahai AV. Randomized, doubleblind, controlled trial of early endoscopic ultrasound-guided celiac plexus neurolysis to prevent pain progression in patients with newly diagnosed, painful, inoperable pancreatic cancer. J Clin Oncol. 2011;29:3541-3546.

42. Puli SR, Reddy JB, Bechtold ML, Antillon MR, Brugge WR. EUS-guided celiac plexus neurolysis for pain due to chronic pancreatitis or pancreatic cancer pain: a meta-analysis and systematic review. Dig Dis Sci. 2009;54:2330-2337.

43. Sahai AV, Lemelin V, Lam E, Paquin SC. Central vs. bilateral endoscopic ultrasound-guided celiac plexus block or neurolysis: a comparative study of shortterm effectiveness. Am J Gastroenterol. 2009;104:326-329.

44. Levy MJ, Topazian MD, Wiersema MJ, et al. Initial evaluation of the efficacy and safety of endoscopic ultrasound-guided direct Ganglia neurolysis and block. Am J Gastroenterol. 2008;103:98-103.

45. Sakamoto H, Kitano M, Kamata K, et al. EUS-guided broad plexus neurolysis over the superior mesenteric artery using a 25-gauge needle. Am J Gastroenterol. 2010;105:2599-2606.
46. Yan BM, Myers RP. Neurolytic celiac plexus block for pain control in unresectable pancreatic cancer. Am J Gastroenterol. 2007;102:430-438.

47. Eisenberg E, Carr DB, Chalmers TC. Neurolytic celiac plexus block for treatment of cancer pain: a meta-analysis. Anesth Analg. 1995;80:290-295.

48. Gunaratnam NT, Sarma AV, Norton ID, Wiersema MJ. A prospective study of EUS-guided celiac plexus neurolysis for pancreatic cancer pain. Gastrointest Endosc. 2001;54:316-324.

49. Iwata K, Yasuda I, Enya M, et al. Predictive factors for pain relief after endoscopic ultrasound-guided celiac plexus neurolysis. Dig Endosc. 2011;23:140-145.

50. Ascunce G, Ribeiro A, Reis I, et al. EUS visualization and direct celiac ganglia neurolysis predicts better pain relief in patients with pancreatic malignancy (with video). Gastrointest Endosc. 2011;73:267-274.

51. O’Toole TM, Schmulewitz N. Complication rates of EUS-guided celiac plexus blockade and neurolysis: results of a large case series. Endoscopy. 2009;41:593-597. 52. Varadarajulu S, Jhala NC, Drelichman ER. EUS-guided radiofrequency ablation with a prototype electrode array system in an animal model (with video). Gastrointest Endosc. 2009;70:372-376.

53. Yusuf TE, Matthes K, Brugge WR. EUS-guided photodynamic therapy with verteporfin for ablation of normal pancreatic tissue: a pilot study in a porcine model (with video). Gastrointest Endosc. 2008;67:957-961.

54. Sun S, Xu H, Xin J, Liu J, Guo Q, Li S. Endoscopic ultrasound-guided interstitial brachytherapy of unresectable pancreatic cancer: results of a pilot trial. Endoscopy. 2006;38:399-403.

55. Jin Z, Du Y, Li Z, Jiang Y, Chen J, Liu Y. Endoscopic ultrasonography-guided interstitial implantation of iodine 125 -seeds combined with chemotherapy in the treatment of unresectable pancreatic carcinoma: a prospective pilot study. Endoscopy. 2008;40:314-320.

56. Pishvaian AC, Collins B, Gagnon G, Ahlawat S, Haddad NG. EUS-guided fiducial placement for CyberKnife radiotherapy of mediastinal and abdominal malignancies. Gastrointest Endosc. 2006;64:412-417.

57. Yang J, Abdel-Wahab M, Ribeiro A. EUS-guided fiducial placement before targeted radiation therapy for prostate cancer. Gastrointest Endosc. 2009;70: 579-583.

58. Levy MJ, Thompson GB, Topazian MD, et al. US-guided ethanol ablation of insulinomas: a new treatment option. Gastrointest Endosc. 2012;75:200-206.

59. Oh HC, Seo DW, Song TJ, et al. Endoscopic ultrasonography-guided ethanol lavage with paclitaxel injection treats patients with pancreatic cysts. Gastroenterology. 2011;140:172-179.

60. DeWitt J, McGreevy K, Schmidt CM, Brugge WR. EUS-guided ethanol versus saline solution lavage for pancreatic cysts: a randomized, double-blind study. Gastrointest Endosc. 2009;70:710-723.

61. DeWitt J, DiMaio CJ, Brugge WR. Long-term follow-up of pancreatic cysts that resolve radiologically after EUS-guided ethanol ablation. Gastrointest Endosc. 2010;72:862-866

62. Chang KJ, Nguyen PT, Thompson JA, et al. Phase I clinical trial of allogeneic mixed lymphocyte culture (cytoimplant) delivered by endoscopic ultrasoundguided fine-needle injection in patients with advanced pancreatic carcinoma. Cancer. 2000;88:1325-1335.

63. Chang KJ, Lee JG, Holcombe RF, Kuo J, Muthusamy R, Wu ML. Endoscopic ultrasound delivery of an antitumor agent to treat a case of pancreatic cancer. Nat Clin Pract Gastroenterol Hepatol. 2008;5:107-111.

64. Gonzalez JM, Giacino C, Pioche M, et al. Endoscopic ultrasound-guided vascular therapy: is it safe and effective? Endoscopy. 2012;44:539-542.

65. Levy MJ, Wong Kee Song LM, Kendrick ML, Misra S, Gostout CJ. EUSguided coil embolization for refractory ectopic variceal bleeding (with videos). Gastrointest Endosc. 2008;67:572-574.

66. Weilert F, Shah JN, Marson FP, Binmoeller KF. EUS-guided coil and glue for bleeding rectal varix. Gastrointest Endosc. 2011 Dec 13. Epub ahead of print. 